PHYSICOCHEMICAL CHARACTERISTICS IN DIFFERENT DEGREES OF MATURATION OF THE FRUITS OF THREE PROMISING LINES OF PIŃÓN AND QUALITY OF OIL EXTRACTION FROM SEEDS

\title{
CARACTERÍSTICAS FÍSICOQUÍMICAS EN DIFERENTES GRADOS DE MADURACIÓN DE LOS FRUTOS DE TRES LÍNEAS PROMISORAS DE PIÑÓN Y CALIDAD DE LA EXTRACCIÓN DE ACEITE DE LAS SEMILLAS
}

Gabriela Gallo-Sevillano'; Wilmer Ponce Saltos ${ }^{2}$; Joffre Pincay Menéndez ${ }^{3}$; Andrés Viteri ${ }^{4}$; Rigoberto Fimia Duarte $\&$ Freddy Zambrano Gavilanes ${ }^{6 *}$

1 Universidad Técnica de Manabí, Instituto de Posgrado, Facultad de Ingeniería Agrícola, Portoviejo, Ecuador.

2 Instituto Nacional Autónomo de Investigaciones Agropecuarias. Estación Experimental Portoviejo. Km 12 vía Santa Ana, Manabí, Ecuador. *wilmerhps@hotmail.com/ wilmer.ponce@iniap.gob.ec

Investigador Independiente. Jipijapa, Manabí, Ecuador.

4 Instituto Interamericano de Cooperación para la Agricultura, Km 12 vía Santa Ana, Manabí, Ecuador

5 Facultad de Tecnología de la Salud y Enfermería, Universidad de Ciencias Médicas de Villa Clara, Cuba.

6 Universidad Técnica de Manabí, Facultad de Ingeniería Agronómica, Portoviejo, Ecuador. *freddyzg_86@hotmail. com/ fezambrano@utm.edu.ec

* Corresponding author: freddyzg_86@hotmail.com

\section{ABSTRACT}

In this work, the behavior and physicochemical characteristics of fruits, seeds, and the oil extracted from three promising sprocket lines CP041, СP052, and CP054 with degrees of maturation were evaluated: light green, yellow, yellowish-brown, and dark brown. The samples were obtained from the germplasm bank of the Portoviejo Experimental Station of the National Institute for Agricultural Research (INIAP-EEP), Manabí, Ecuador. In the statistical analysis, it was determined that the ripe fruits were the ones that presented the highest percentage of oil content, being the line CP041 the one that presented the highest content. In the percentage of seeds in nuts, the CP041 line had a higher yield than the CP054 line. As for proteins, the CP041 line stood out, in the percentage of fiber and humidity CP052 and the percentage of ash CP054. In line CP041, the light green fruit oil had a higher iodine index and a saponification index. The kinematic viscosity in the yellow fruit was the most outstanding with the other degrees of ripening. The yellowish-brown fruits presented the lowest acidity index. When the fruits studied were dark browns, there was a lower peroxide index and a lower range relative density. The fruits with the highest content of double bonds referring to the Iodo index were light green fruits in line CP052, while in line CP054 they were dark brown fruits. The dried fruits (dark brown) of the line CP052 and CP054 reached a high saponification index in relation to the other degrees of ripeness. The values shown in the kinematic viscosity in the 
yellowish-brown fruits stand out from the other ripening stages in both the CP052 and CP054 lines. In relative density, both in lines CP052 and CP054, the yellow-green fruits stand out in relation to the other ripening stages.

Keywords: gene bank - Jatropha curcas - oil quality

\section{RESUMEN}

En este trabajo se evaluó el comportamiento y las características fisicoquímicas de frutos, semillas y aceite extraído de tres líneas promisorias de piñón CP041, CP052 y CP054 con grados de maduración siendo estos: verde claro, amarillo, marrón amarillento y marrón oscuro. Las muestras fueron obtenidas del banco de germoplasma de la Estación Experimental Portoviejo del Instituto Nacional de Investigaciones Agropecuarias (INIAP-EEP), Manabí, Ecuador. En el análisis estadístico se determinó que los frutos maduros son los que presentaron mayor porcentaje de contenido de aceite siendo la línea CP041 la que presentó mayor contenido. En el porcentaje de semillas en frutos secos la línea CP041 tuvo más rendimiento a diferencia que la línea CP054. En cuanto a las proteínas, la línea CP041 tuvo destaque, en porcentaje de fibra y en humedad CP052 y en porcentaje de cenizas CP054. En la línea CP041 el aceite de los frutos verdes claro tuvo mayor índice de yodo y de índice de saponificación. La viscosidad cinemática en el fruto amarillo fue el más sobresaliente con los demás grados de maduración. Los frutos marrones amarillento presentaron el menor índice de acidez. Cuando los frutos estudiados eran los marrones oscuros existió menor índice de peróxidos y de la densidad relativa de menor magnitud de rangos. Los frutos con mayor contenido de dobles enlaces referente al índice de Iodo fueron los frutos verde claros en la línea CP052, mientras que en la línea CP054 fueron los frutos marrón oscuros. Los frutos secos (marrón oscuro) de la línea CP052 y CP054 alcanzaron un elevado índice de saponificación en relación con los otros grados de maduración. Los valores arrojados en la viscosidad cinemática en los frutos marrón amarillento sobresalen a los otros estados de maduración tanto en la línea CP052 y CP054. En la densidad relativa, tanto en las líneas CP052 y CP054, resalta los frutos verde amarillos en relación con los demás estados de maduración.

Palabras clave: banco de germoplasma - calidad de aceite - Jatropha curcas

\section{INTRODUCCIÓN}

Actualmente, muchos países del mundo se centran en fuentes de energía alternativas para superar los principales desafíos debido al rápido agotamiento de las reservas de petróleo y los efectos adversos de las emisiones de gases de efecto invernadero (Kumar et al., 2018). Algunas estrategias para reducir la dependencia de los combustibles fósiles es que el mundo tiene que cambiar la energía de producción basada en fuentes fósiles a una basada en fuentes renovables (Rodríguez-Ramos et al., 2018). Las fuentes energías renovables son fuentes basadas en la biomasa vegetal que se han convertido cada vez más importante entre las fuentes emergentes de energía renovable (Gomes et al., 2018).

En este contexto en el caso del piñón (Jatropha curcas Linnaeus) por su alto contenido de aceite, puede ser utilizado como biocombustibles (Karaj \& Müller, 2018). En el Ecuador actualmente existe el Proyecto "Piñón para Galápagos", con el compromiso de conservación del ecosistema insular con la iniciativa "Cero Combustibles Fósiles para Galápagos" con el fin de evitar los riesgos de derrames de combustibles, y el cambio de la matriz energética, esto se lleva a cabo con el aprovechamiento de las cercas vivas de piñón (IICA, 2018).

El piñón pertenece a la familia Euphorbiaceae, y su género comprende alrededor de 500 especies. La especie es diploide con $2 \mathrm{n}=2 \mathrm{x}=22$ cromosomas. Es probable que el centro de origen sea en América Central, pero está ocurriendo ampliamente en varias partes del mundo, como América del Sur, África y Asia (Pinto et al., 2018). Es un cultivo perenne adecuado para las zonas tropicales y subtropicales y tiene un potencial considerable para el uso de su aceite de semilla como fuente alternativa 
sostenible de biocombustibles (Alburquerque et al., 2017).

Las semillas de Jatropha (Linnaeus, 1753) se destacan por tener un alto contenido de aceite para el uso de biocombustible, eficiencia de conversión en comparación con otras especies, tolerancia a la sequía, rápido crecimiento y fácil propagación, la posibilidad de cultivo en altitudes elevadas y vida útil de producción de más de 50 años (Alves et al., 2018).

El aceite de piñón puede extraerse mediante diferentes métodos (Zambrano et al., 2015); sin embargo, los métodos de extracción mecánica, generalmente se prefieren porque los costos operativos son bajos y puede ser realizado fácilmente por operadores semi-calificados, a pesar de que la extracción es menor que los métodos de extracción con solventes químicos.

En efecto, la tasa de recuperación de aceite obtenida por métodos de prensado mecánico es comprendido entre 69 y $86 \%$ mientras que el rendimiento obtenido por clásico, los disolventes orgánicos, como el n-hexano, comprenden métodos de extracción entre 70 y 99\% dependiendo del tiempo de extracción y el tipo de solvente (Mouahid et al., 2018).

El presente estudio consistió en determinar algunas características físicoquímicas en diferentes grados de maduración de frutos de tres líneas promisoras de piñón y calidad de la extracción de aceite de las semillas.

\section{MATERIALES Y MÉTODOS}

La presente investigación fue realizada en las instalaciones del laboratorio de Biocombustibles del del Instituto Nacional de Investigaciones Agropecuarias (INIAP), Estación Experimental Portoviejo (EEP), localizado en la parroquia Colón, cantón Portoviejo provincia de Manabí, Ecuador

\section{Materiales}

\section{Material Vegetal}

Los frutos utilizados para los análisis fueron obtenidos de tres líneas promisorias, CP041, CP052 y CP054 pertenecientes al banco de Germoplasma de Piñón del INIAP. El área en el que se encuentra implando el banco (Figura 1) tiene un suelo clasificado como franco limoso con temperatura media anual (ma) de $24,6^{\circ} \mathrm{C}$, humedad relativa (ma) de $82 \%$, precipitación (ma) $550 \mathrm{~mm}$ y altitud $44 \mathrm{msnm}$, siendo sus coordenadas geográficas $0,1^{\circ}$ de latitud Sur y 80 23' de longitud Oeste. Los análisis físicos y químicos fueron efectuados en el Biocombustibles de la misma institución.

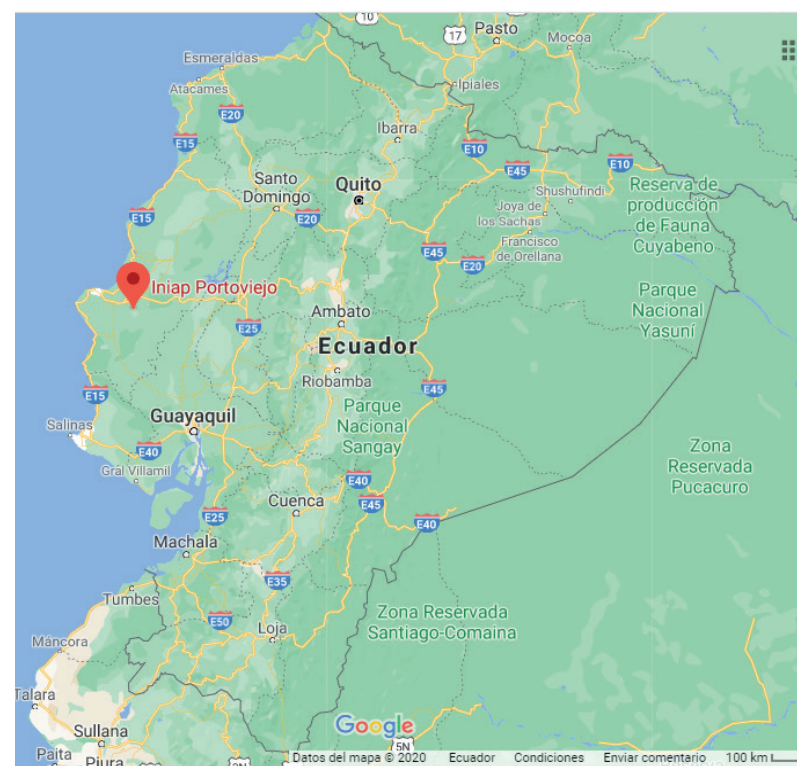

Figura 1. Ubicación del banco de germoplasma de la colección de germoplasma de piñón (Jatropha curcas) de la estación experimental Portoviejo del INIAP, Provincia de Manabí, Ecuador.

\section{Métodos de análisis}

\section{Análisis Físicos y Químicos}

Para los diferentes análisis físico-químicos fueron separados 30 frutos de acuerdo al grado de maduración en el cual, se efectuó la relación cáscara-semilla, con los procedimientos de pesar los frutos en una balanza analítica marca ADAM (Legibilidad 0,01mg/ 0,1mg para $0,0001 \mathrm{~g}$ ) para luego descascarar, volver a pesar y contabilizar el número de semillas.

El análisis de las semillas fue realizado como lo manifiesta la AOAC (1990) con ciertas modificaciones. El análisis de humedad de los frutos y semillas se efectuó a través del método de secado en estufa marca PRECISION, a $105 \pm 2{ }^{\circ} \mathrm{C}$ por $24 \mathrm{hs}$; la grasa total o contenido de aceite por el método soxhlet, utilizando como solvente el n-hexano. La determinación de cenizas se efectuó una calcinación a través de una mufla Termolyne, a 550 $\pm{ }^{\circ} \mathrm{C}$. La proteína cruda por medio del Microkjeldahl Labconco se hizo una digestión ácida (con ácido sulfúrico concentrado y un catali) y básica (hidróxido de sodio al 40\%), luego se tituló con ácido clorhídrico 
al 0,02 $\mathrm{N}$ con ayuda de un indicador. La fibra cruda se estableció a través de un vaso Berzelius de $600 \mathrm{~mL}$ en un equipo digestor fibra Labconco, la digestión es ácida (ácido sulfúrico al 7\%) y básica con hidróxido de sodio al 20\%, para luego filtrar en un crisol Gooch que contiene fibra de vidrio, se secó en una estufa a $105 \pm$ $2{ }^{\circ} \mathrm{C}$ por $24 \mathrm{~h}$ y se calcina a $600{ }^{\circ} \mathrm{C}$ (Rodríguez, 2013).

\section{Extracción de aceite de piñón}

Para obtener el aceite de piñón, se hizo mediante la extracción química del soxhlet en mayor magnitud, realizando una homogenización de las semillas a través de un molino de discos, para luego encapsularlo en una bolsa de papel filtro sellada con grapas, que automáticamente va dentro de un sifón soxhlet, el balón es llenado con el solvente n-hexano, acoplando el sistema con su respectivo condensador y plancha de calentamiento, que una vez instalado, el proceso de destilación del solvente y recirculando dentro del sistema por un periodo aproximado de seis horas, adquiriendo el aceite deseado para las caracterizaciones posteriores.

\section{Métodos para Análisis de la Calidad de Aceite}

Los ácidos grasos libres (AGL) o índice de acidez se realizó por medio de la norma AOCS Ca 5a-40, titulando con hidróxido de potasio $0,1 \mathrm{~N}$ valorizado con un indicar de fenolftaleína (Rodríguez, 2013), define como el "número de $\mathrm{mg}$ de hidróxido de potasio necesarios para saponificar 1 g de grasa” el análisis del índice de saponificación (IS) través de un medio alcohólico-alcalino bajo un sistema de reflujo, se titula con ácido clorhídrico al $0,5 \mathrm{~N}$ con un indicador de fenolftaleína.

El análisis del índice de yodo se lo hizo a través de la norma AOCS Cd 1-25, que recomienda el método de Wijs que se titula con solución de tiosulfato de sodio $0,1 \mathrm{~N}$ y como indicador almidón diluido con agua. El índice de peróxidos (AOCS Cd 8-53) análisis nos permitió indicar en que parte del experimento el aceite contiene rancidez oxidativa a través de un medio cloro/ acético, que se tituló con solución de tiosulfato de sodio $0,1 \mathrm{~N}$, y como indicador se utilizó solución de almidón en agua.

En la viscosidad cinemática ASTM D-445 (2017), se utilizó el viscosímetro de Cannon-Fenske para líquidos newtonianos transparentes y opacos, a través de un baño maría a una temperatura de $40^{\circ} \mathrm{C}$ que consiste en calcular el tiempo de descarga de un bulbo a otro.

\section{Análisis Estadístico}

El ensayo se realizó mediante un diseño completamente al azar en cuatro repeticiones. Para los resultados fue efectuado un análisis de varianza (ADEVA), la comparación de las medias de los tratamientos fue mediante la prueba de Tukey $(\mathrm{p}<0,05)$, mediante el software estadístico Infostat (Di Rienzo et al., 2018).

\section{Aspectos éticos}

La investigación estuvo sujeta a normas éticas que posibilitaron promover y asegurar el respeto de todos los participantes en el estudio, de modo que se respetaron sus criterios/opiniones y derechos individuales, para poder generar nuevos conocimientos sin violar los principios éticos de la intimidad y confidencialidad de la información personal, de todos los participantes en la investigación. El estudio posibilitó reducir al mínimo el daño posible al ambiente, así como al ecosistema objeto de estudio y de esta forma poder generar nuevos conocimientos sin violar los principios éticos establecidos para estos casos. Por otra parte, todos los autores involucrados en la investigación, publicación y difusión de los resultados, somos responsables de la confiabilidad y exactitud de los resultados mostrados (DHAMM, 2013).

\section{RESULTADOS Y DISCUSIÓN}

\section{Análisis Físico-Químicas de los Frutos y Semillas de Pińón}

Analizando el Peso de fruto, fueron encontradas diferencias significativas en las tres líneas CP041, CP052, CP054. En la CP041 se muestra que mayor peso tienen cuando el fruto es verde claro y amarillo, al igual que en la línea CP052 presentan mayor peso los frutos en esos estados. Ya para la CP054 los frutos verdes claro, amarillo y marrón amarillentos tuvieron más peso que los frutos marrón oscuros (Figura 2).

Con relación al peso de semillas en la CP041 se alcanzó mayor peso de semillas en los frutos amarillos, marrón amarillento y verdes claro diferenciándose de los frutos marrón oscuro, al igual en que en la CP054. En la CP052 se muestran valores superiores en el peso en los frutos verde claro y amarillo siendo diferentes de los otros estados (Figura 1).

Con respecto al número de semillas por fruto no fueron encontradas diferencias en ninguno de los 
estados de frutos para las líneas CP041 ya para la CP054 se encontró menor número de semillas en los frutos verde claros y mayor número en los otros estados (Figura 2).

En el porcentaje de semilla se demostró que en el estado de frutos marrón oscuro tuvieron mayor porcentaje que en los otros estados, independientemente de las líneas estudiadas (Figura 2).

Según Salviano dos Santos (2010), la media de cada fruto de piñón seco (marrón oscuro) es $2,46 \mathrm{~g}$ ( $73,8 \mathrm{~g}$ en los 30 frutos aproximadamente), una media de semillas de 2,6 unidades de semillas por fruto (entre 2 y 3 unidades) y el $\%$ de semilla que corresponde al 55\% del peso al fruto seco, en los cuales, existe diferencia entre variedades como se aprecia en la figura 2.

En la Figura 2 se encuentra el porcentaje de aceite de las semillas, en que se puede observar que no existieron diferencias estadísticas en los tratamientos, mismo así se puede mencionar que los valores variaron entre 29,71\% (CP052 frutos marrón oscuro) y 39,17 \% (CP041 en frutos amarillos). Cremonez et al. (2017) menciona que el contenido de aceite en las etapas de maduración más adecuadas para la cosecha de piñón se encuentra inmediatamente después del amarilleo de las frutas, cuando tienen una mayor cantidad de aceite, lo que no se pudo evidenciar en nuestro estudio. Igualmente, los resultados difieren de Garay et al. (2012), que encontraron 49,76\% en frutos verdes amarillos, $51,19 \%$ en amarillos y $51,27 \%$ en marrón amarillento y 47,38\% en marrón oscuros. Frausches dos Santos (2011) en el contenido de aceite en verde que es 6-26\% (verde oscuro) presentaron una alta variabilidad (base seca) relacionados a este estudio, sin embargo, para los otros estados de maduración, está dentro del rango, entre ellos: 22-40\% Amarillo, 26$40 \%$ (amarillo oscuro) y 20-43\% (marrón amarillento), rangos similares a los resultados encontrados en la presente investigación.

En la figura 3 se muestran algunas características bromatológicas de frutos de piñón de tres líneas promisorias con diferentes grados de maduración. Analizando las proteínas diferencias fueron encontradas en cada una de las variedades evaluadas. Mayor porcentaje de proteínas fue encontrado en los frutos amarillos, marrón amarillento y marrón oscuro que en los frutos verde claro en la línea CP041. Estudiando la línea CP052 valores más altos fueron obtenidos en los frutos verde claro y amarillos que los otros dos estados. En cuanto a la CP054 porcentajes de proteínas menores se encontraron en los frutos amarillos siendo diferentes de los otros estados (Figura 3). En torta detoxificada de piñón, Ahluwalia et al. (2019) en base a un sinnúmero de estudios consiguieron extraer $41,98 \%$ de proteínas de la torta, además determinaron que contiene alto porcentaje de aminoácidos lo que es muy atractivo para la alimentación animal. Vaknin et al. (2011) comparando diferentes semillas de piñón de diversos orígenes (Surinam, Nigeria, Brazil, China y Etiopía) consiguieron contenidos de proteínas de 20,42 a 28,68 $\%$ de proteínas, cabe mencionar que fueron obtenidas de frutos secos (marrón oscuro) siendo porcentajes inferiores a los frutos secos de las tres líneas estudiadas en la presente investigación CP041 con 56,21\% de proteínas, CP052 con 38,69\% y CP054 con 40,31\% originarias de Ecuador.

En el porcentaje de cenizas, no hubo diferencias significativas en los estados de los frutos para la línea CP052. Ya para la CP041 mayores efectos en esta variable fueron encontrados en los frutos marrón oscuro y marrón amarillento. En la CP054 valores más bajos se encontraron en los frutos marrón amarillentos que en los otros evaluados (Figura 3).

Referente al porcentaje de fibra no se encontraron diferencias entre las líneas estudiadas, mismo así se puede mencionar valores más altos en la CP052 (Figura 3).

En la Figura 3 se observa el porcentaje de humedad de tres líneas promisorias de piñón en base a sus estados de maduración. Las líneas CP041 y CP052 tuvieron un comportamiento parecido en base a esta variable, con menor humedad en los frutos secos (marrón oscuro), mientras que en los otros estados se encontró más humedad. En la CP054 mayor porcentaje de humedad fue encontrado en el fruto verde claro siendo diferente de los otros estados de maduración de los frutos (Figura 3). En esta especie de planta como en muchas otras, la maduración de los frutos hace que comiencen a senescencia, causando una pérdida drástica de humedad, de modo que cuando se seca (Cremonez et al., 2017). 


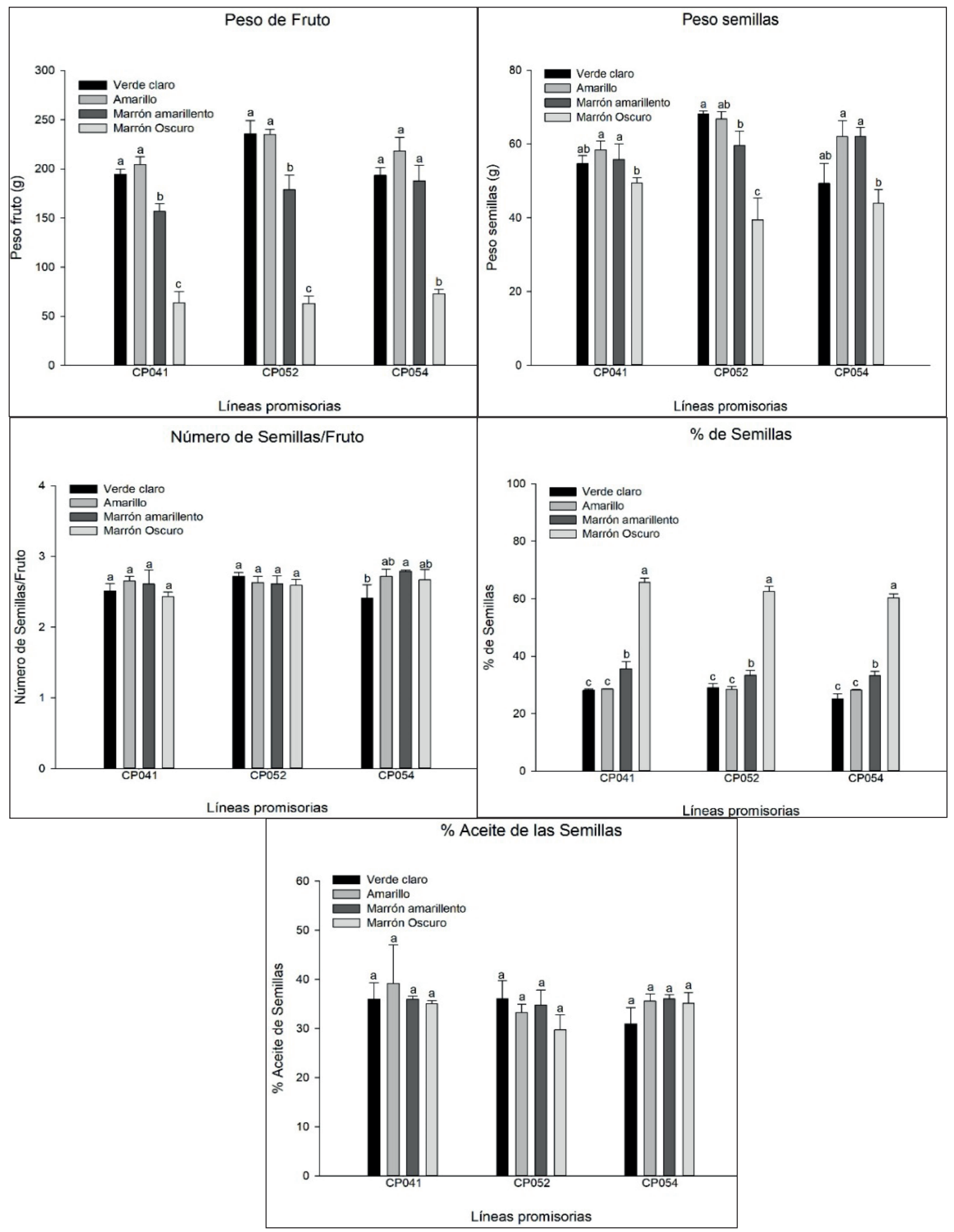

Figura 2. Caracterización física y química de frutos de piñón de tres líneas promisorias con diferentes grados de maduración. 


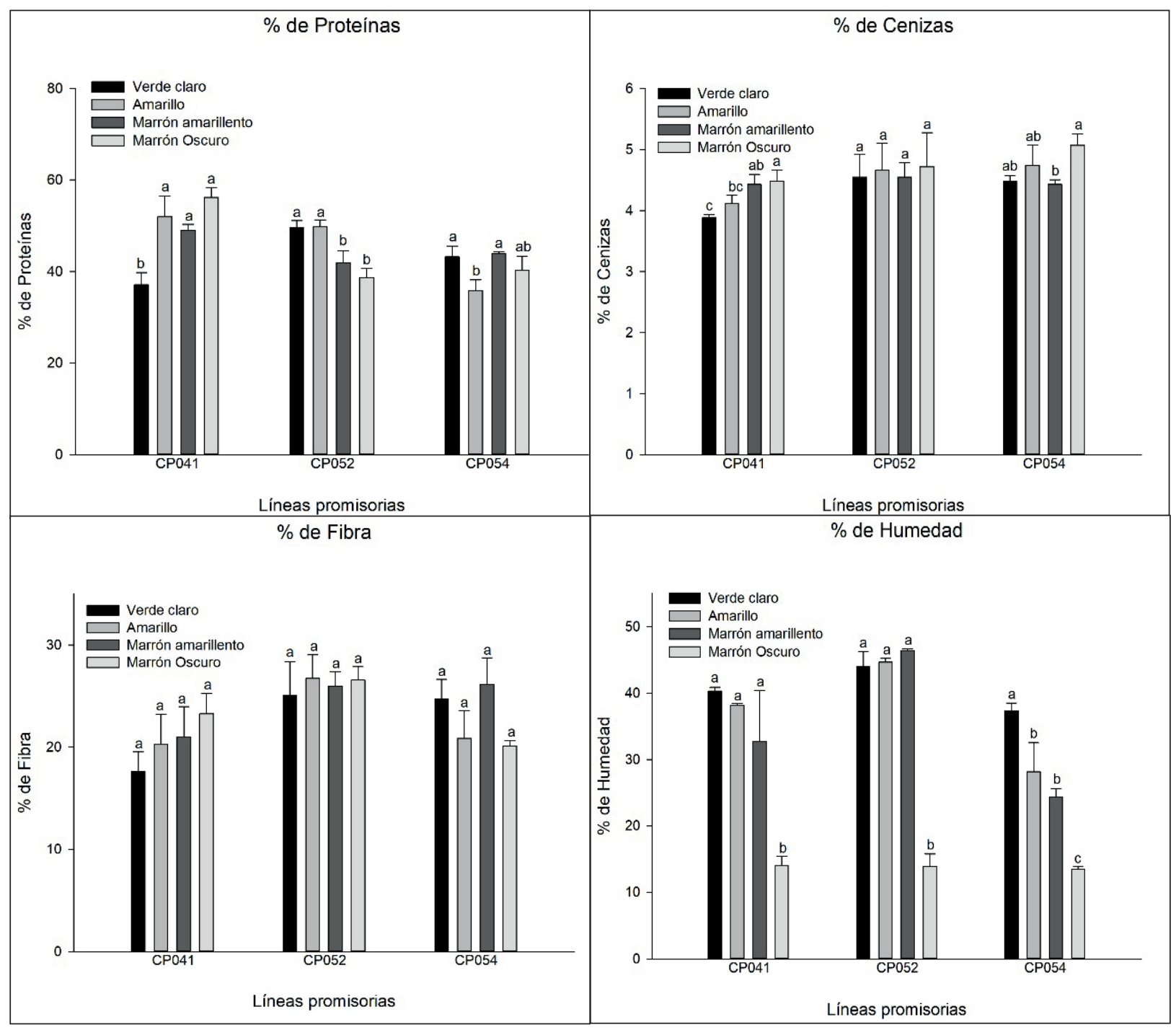

Figura 3. Características bromatológicas de frutos de piñón de tres líneas promisorias con diferentes grados de maduración.

\section{Calidad del aceite de las semillas de piñón}

Efectos significativos fueron encontrados en el índice de acidez para las tres líneas estudiadas (Tabla 1). Menor acidez fue encontrada en los frutos amarillos, marrón amarillento y marrón oscuro de la línea CP041. Analizando la línea CP052 menor acidez se encontró en los frutos verde claro, amarillo y marrón oscuro y para CP054 es el marrón amarillento tuvo menor acidez. El Índice de acidez (IA) es el número de mg de $\mathrm{KOH}$ necesario para neutralizar los AGL (que no se encuentran unidos a un glicérido) de $1 \mathrm{~g}$ de aceite. Se determina mediante la 14 titulación o valoración del aceite disuelto en alcohol con una solución estándar de $\mathrm{KOH}$. El valor del IA refleja el contenido de AGL, producto de la hidrólisis (Di Pietro et al., 2020). El IA determinado en el biodiesel es importante para determinar el nivel de AGL o ácidos presentes, pues refleja la calidad del biodiesel, ya que si este índice es alto, incrementa los depósitos en el sistema de combustión e incrementan la potencialidad de corrosión del sistema.

Santos et al. (2012) mencionan que la acidez tiende a aumentar a medida que la fruta alcanza etapas más avanzadas de maduración, es decir, las frutas completamente marrones tienden a tener una mayor acidez, lo que no es interesante considerando el uso industrial del aceite, lo que sucedió en la presente investigación en las líneas CP052 y CP054 a diferencia de la línea CP041.

En el índice de peróxidos (Tabla 1), se muestra que en la línea CP041 menor índice existió en el fruto marrón oscuro, en la CP052 en los frutos amarillos, marrón amarillento y 
marrón oscuro. En la línea CP054 se demostró que los frutos marrones amarillentos tuvieron menor índice. El índice de peróxido (IP) mide el grado de oxidación primaria que ha sufrido la grasa o aceite. Los peróxidos son los productos de descomposición primaria de la oxidación de las grasas. Se forman en los dobles enlaces de las cadenas de carbonos de los ácidos grasos (Villanueva et al., 2017). Este índice permite determinar todas las sustancias que oxidan el yoduro de potasio en condiciones de la prueba, en términos de miliequivalentes de peróxido por $\mathrm{kg}$ de muestra (Charles et al., 2020). Analizando el índice de iodo, de saponificación y la viscosidad cinemática no se encontraron diferencias significativas en las líneas CP041 y CP052 (Tabla 1).

En la línea CP054 fueron encontradas diferencias siendo que menores valores fueron encontrados en los frutos marrón amarillento en el índice de yodo (IY) (Tabla 1), que es el número de miliequivalentes o partes de yodo absorbido por 100 partes de peso de sustancia. Este valor da una idea del número de instauraciones de los ácidos grasos en el aceite. Un aceite totalmente saturado poseerá un IY igual a 0 , mientras que a mayor cantidad de instauraciones se fijará en ellos una cantidad proporcional de yodo, incrementándose este índice (Guerrero-Chuquilin, 2019).
En el índice de saponificación (IS), los frutos amarillos tuvieron menor índice de saponificación (Tabla 1). Un aceite es el número de miligramos de hidróxido de potasio $(\mathrm{KOH})$ necesarios para saponificar $1 \mathrm{~g}$ de aceite. Desde que los triglicéridos son los componentes mayoritarios de los aceites, y que cada triglicérido necesita tres moléculas de $\mathrm{KOH}$ para saponificarse, el IS puede ser usado para calcular aproximadamente el peso molecular promedio del aceite (Jain et al., 2020).

En cuanto a la viscosidad cinemática, se encontraron menores valores en los frutos verde claro y marrón oscuro (Tabla 1), la cual se define como la resistencia del líquido a fluir y es la más importante característica del combustible. Ella afecta la operación de inyección del combustible, formación de mezclas y procesos de combustión. La alta viscosidad interfiere con el proceso de inyección e induce a una insuficiente atomización del combustible (Kim \& Lim, 2020).

Valores similares a los determinados en la presente investigación fueron encontrados por García-Muentes et al. (2018) quien efectuó las mismas variables analizadas.

Tabla 1. Calidad del aceite de las semillas de piñón.

\begin{tabular}{|c|c|c|c|c|c|c|c|c|c|c|}
\hline \multirow{2}{*}{ Estado } & \multicolumn{2}{|c|}{$\begin{array}{l}\text { Índice de } \\
\text { Acidez } \\
\end{array}$} & \multicolumn{2}{|c|}{$\begin{array}{l}\text { Índice de } \\
\text { Peróxidos } \\
\end{array}$} & \multicolumn{2}{|c|}{$\begin{array}{l}\text { Índice de } \\
\text { Iodo }\end{array}$} & \multicolumn{2}{|c|}{$\begin{array}{c}\text { Indice de } \\
\text { saponificación }\end{array}$} & \multicolumn{2}{|c|}{$\begin{array}{l}\text { Viscosidad } \\
\text { cinemática }\end{array}$} \\
\hline & \multicolumn{10}{|c|}{ línea CP041 } \\
\hline Verde claro & 1,71 & A & 19,95 & B & 95,43 & A & 185,77 & A & 35,14 & A \\
\hline Amarillo & 1,08 & $\mathrm{~B}$ & 31,87 & A & 92,88 & A & 183,51 & A & 33,83 & A \\
\hline Marrón amarillento & 0,92 & $\mathrm{~B}$ & 3,40 & $\mathrm{C}$ & 91,61 & A & 169,73 & A & 35,51 & A \\
\hline Marrón oscuro & 1,26 & B & 1,20 & $\mathrm{D}$ & 90,89 & A & 181,30 & A & 35,42 & A \\
\hline $\mathrm{CV}$ & 12,52 & & 3,69 & & 2,09 & & 3,71 & & 1,82 & \\
\hline \multirow[t]{2}{*}{$\mathrm{p}$} & 0,00 & & 0,00 & & 0,07 & & 0,09 & & 0,06 & \\
\hline & \multicolumn{10}{|c|}{ línea CP052 } \\
\hline Verde claro & 1,03 & B & 1,39 & A & 110,41 & A & 201,03 & A & 32,44 & A \\
\hline Amarillo & 1,53 & $\mathrm{~B}$ & 0,66 & B & 112,77 & A & 199,16 & A & 32,62 & A \\
\hline Marrón amarillento & 1,53 & B & 0,87 & $\mathrm{AB}$ & 106,28 & A & 186,82 & A & 31,88 & A \\
\hline Marrón oscuro & 3,57 & A & 0,66 & B & 113,44 & A & 180,46 & A & 32,05 & A \\
\hline $\mathrm{CV}$ & 22,63 & & 27,58 & & 5,45 & & 6,77 & & 1,32 & \\
\hline \multirow[t]{2}{*}{$\mathrm{p}$} & 0,00 & & 0,03 & & 0,51 & & 0,26 & & 0,23 & \\
\hline & \multicolumn{10}{|c|}{ línea CP054 } \\
\hline Verde claro & 0,33 & $\mathrm{AB}$ & 2,18 & A & 116,63 & A & 178,96 & A & 29,74 & B \\
\hline Amarillo & 0,38 & A & 1,32 & B & 110,03 & A & 172,23 & B & 31,91 & A \\
\hline Marrón amarillento & 0,25 & B & 0,44 & $\mathrm{D}$ & 92,15 & B & 177,46 & $\mathrm{AB}$ & 31,89 & A \\
\hline Marrón oscuro & 0,28 & $\mathrm{AB}$ & 0,66 & $\mathrm{C}$ & 104,01 & $\mathrm{AB}$ & 176,72 & $\mathrm{AB}$ & 30 & $\mathrm{~B}$ \\
\hline $\mathrm{CV}$ & 14,24 & & 0,25 & & 4,39 & & 1,12 & & 1,49 & \\
\hline $\mathrm{p}$ & 0,05 & & 0,00 & & 0,00 & & 0,03 & & 0,00 & \\
\hline
\end{tabular}


Se concluye que el contenido de aceite en la Línea CP041 es mayor respecto a las medias de las otras líneas, los frutos maduros son los que presentan mayor porcentaje. El \% de Semillas en Frutos Secos la Línea CP041 es de mayor rendimiento, y la Línea CP054 de más unidades de semilla en el fruto. En 30 frutos, la línea CP052 presentan mayor peso de frutos y semillas. Finalmente, en Proteínas, la media de la Línea CP041 es mayor, en \% Fibra y Humedad la Línea CP052 y en \% de Cenizas la Línea CP054.

\section{REFERENCIAS BIBLIOGRÁFICAS}

Alburquerque, N.; García-Almodóvar, R.C., Valverde, J.M.; Burgos, L. \& Martínez-Romero, D. 2017. Characterization of Jatropha curcas accessions based in plant growth traits and oil quality. Industrial Crops and Products, 109: 693-698.

Alves, R.S.; de Azevedo Peixoto, L.; Teodoro, P. E.; Silva, L.A.; Rodrigues, E.V. de Resende, M. D. V., Laviola, B.G. \& Bhering, L.L. 2018. Selection of Jatropha curcas families based on temporal stability and adaptability of genetic values. Industrial Crops and Products, 119: 290-293.

Ahluwalia, S.; Bidlan, R.; Shrivastav, A.K.; Goswami, R.K.; Singh, P. \& Sharma, J. G. 2019. Optimization of protein extraction from detoxified Jatropha seed cake using response surface methodology and amino acid analysis. International Journal of Environmental Science and Technology, 17: 1187-1100.

AOCS, O. 1990. Tentative Methods of the American Oil Chemists'Society. American Oil Chemists Society Press, Champaign.

ASTM. 2017. D445-17, Standard Test Method for Kinematic Viscosity of Transparent and Opaque Liquids (and Calculation of Dynamic Viscosity). ASTM International, West Conshohocken, PA.

Charles, A. L.; Abdillah, A. A.; Saraswati, Y. R.; Sridhar, K.; Balderamos, C.; Masithah, E. D. \& Alamsjah, M. A. 2020. Characterization of freeze-dried microencapsulation tuna fish oil with arrowroot starch and maltodextrin. Food Hydrocolloids, 112:1-8.

Cremonez, F.E.; Tessele, A.; Missio, R.F.; Cremonez, P.A. \& Miranda, V.T. 2017. Estádios de maturação de frutos de pinháo manso visando maior rendimento no teor de óleo. Revista Brasileira de Energias Renováveis, 6: 940-954.

DHAMM (Declaración de Helsinki de la AMM). 2013. Principios éticos para las investigaciones médicas en seres humanos. 64a Asamblea General, Fortalez, Brazil, octubre. World Medical Association, Inc. - All Rights reserved. 9 pp.

Di Pietro, M. E.; Mannu, A. \& Mele, A. 2020. NMR Determination of Free Fatty Acids in Vegetable Oils. Processes, 8:1-15.

Di Rienzo, J.A.; Casanoves, F.; Balzarini, M.G.; Gonzalez, L.; Tablada, M. \& Robledo, C.W. 2018. InfoStat version 2018. Centro de Transferencia InfoStat, FCA, Universidad Nacional de Córdoba, Argentina.

Garay, R.; Hidalgo, E.; Alegría, J.A \& Mendieta, O.W. 2012. Determinación de Periodos Fisiológicos en la Maduración y Calidad del Aceite de Piñón Blanco (Jatropha curcas L.). Información tecnológica, 23: 53-64.

García-Muentes, S.A.; Lafargue-Pérez, F.; LabradaVázquez, B.; Díaz-Velázquez, M. \& Sánchez del Campo-Lafita, A.E. 2018. Propiedades fisicoquímicas del aceite y biodiesel producidos de la Jatropha curcas L. en la provincia de Manabí, Ecuador. Revista Cubana de Química, 30: $142-158$.

Gomes, T.G.; Hadi, S.I.; Costa Alves, G.S.; Mendonça, S.; De Siqueira, F.G. \& Miller, R.N. 2018. Current strategies for the detoxification of Jatropha curcas seed cake: a review. Journal of agricultural and food chemistry, 66: 2510-2522.

Guerrero-Chuquilin, Y. 2019. Optimización del proceso de transesterificación convencional del aceite de piñón blanco (Jatropha curcas L.) aplicando nuevos parámetros de concentración de metanol e hidróxido de sodio. Tesis para optar el título profesional de Ingeniero Agroindustrial. Universidad Nacional de San Martín -Tarapoto. Perú.

IICA (Instituto Interamericano de Cooperación para la Agricultura). 2018. Representación en Ecuador Convenio BID-FOMIN-MEER-IICA Proyecto Piñón. Obtenido de http://ecuadordesarrollo. com/wp-content/uploads/2018/07/ T\%C3\%A9rminos-Referencia-PromotorAgr\%C3\%ADcola-Social-Pi\%C3\%B 1 onjulio2018.pdf 
Jain, A.; Jain, R. \& Jain, S. 2020. Fat Characterization. In Basic Techniques in Biochemistry, Microbiology and Molecular Biology. Humana, New York, NY. 265-272.

Karaj, S. \& Müller, J. 2010. Determination of physical, mechanical and chemical properties of seeds and kernels of Jatropha curcas L. Industrial Crops and Products, 32: 129-138.

Kim, K. \& Lim, O. 2020. Investigation of the spray development process of gasoline-biodiesel blended fuel sprays in a constant volume chamber. Energies, 13:2-22.

Kumar, R.; Goel, V. \& Kumar, A. 2018. Investigation of heat transfer augmentation and friction factor in triangular duct solar air heater due to forward facing chamfered rectangular ribs: A CFD based analysis. Renewable Energy, 115: 824-835.

Mouahid, A.; Bouanga, H.; Crampon, C. \& Badens, E. 2018. Supercritical $\mathrm{CO}_{2}$ extraction of oil from Jatropha curcas: An experimental and modelling study. The Journal of Supercritical Fluids, 141: 2-11.

Pinto, M.S.; Damasceno-Junior, P.C.; Oliveira, L.C.D.; Machado, A.F.D.F; Souza, M.A.A.D.; Muniz, D.R. \& Dias, L.A.D. S. 2018. Diversity between Jatropha curcas L. accessions based on oil traits and X-ray digital images analysis from it seeds. Crop Breeding and Applied Biotechnology, 18: 292-300.

Rodríguez, J.J. 2013. Química y Análisis Químico. Cano Pina S.L. Barcelona. España.
Rodríguez-Ramos, P.A.; Zumalacarregui De Cárdenas, L.; Perez Ones, O.; Piloto-Rodríguez, R. \& MeloEspinosa, E. A. 2018. Life cycle assessment of biodiesel from Jatropha curcas L oil. A case study of Cuba. Energy Sources, Part A: Recovery, Utilization, and Environmental Effects, 40: 1833-1841.

Santos, S. B.D.; Martins, M.A.; Aguilar, P.R.; Caneschi, A.L.; Carneiro, A.D.C.; \& Dias, L.A.D.S. 2012. Acúmulo de matéria seca e óleo nas sementes de pinhão-manso e qualidade do óleo extraído. Revista Brasileira de Engenharia Agrícola e Ambiental, 16: 209-215.

Vaknin, Y.; Ghanim, M.; Samra, S.; Dvash, L.; Hendelsman, E.; Eisikowitch, D. \& Samocha, Y. 2011. Predicting Jatropha curcas seed-oil content, oil composition and protein content using near-infrared spectroscopy-A quick and non-destructive method. Industrial Crops and Products, 34: 1029-1034.

Villanueva, E.; Rodríguez, G.; Aguirre, E. \& Castro, V. 2017. Influencia de antioxidantes en la estabilidad oxidativa del aceite de chia (Salvia hispanica L.) por rancimat. Scientia Agropecuaria, 8: 19-27.

Zambrano, F.; Delgado, K.; Silva, H.; Nomura, R.B.; Andrade, D. \& Zucareli, C. 2015. Extração e avaliação do óleo de pinhão manso (Jatropha curcas 1.) oriundo das cercas vivas de Manabí Equador. Revista Brasileira de Energias Renováveis, 4: 55-70.

Received September 29, 2020.

Accepted October 24, 2020. 